(c) American Dairy Science Association, 2006.

\title{
Technical Note: Development of a Tool to Insert Abomasal Infusion Lines into Dairy Cows
}

\author{
T. F. Gressley, ${ }^{*}$ S. M. Reynal, ${ }^{\star}$ J. J. Olmos Colmenero, ${ }^{*}$ G. A. Broderick, $†$ and L. E. Armentano*1 \\ *Department of Dairy Science, University of Wisconsin, Madison 53706 \\ †ARS, USDA, US Dairy Forage Research Center, 1925 Linden Drive West, Madison 53706
}

\begin{abstract}
A tool was developed to aid in ruminal insertion of abomasal infusion lines into dairy cows. The tool consisted of 2 pieces cut from polyvinyl chloride pipe. The first piece of pipe, the insertion tool, contained a groove that held the flexible plastic flange that is on the end of the infusion line. The insertion tool containing the flange was inserted into the ruminal cannula, through the sulcus omasi, and into the abomasum. The second piece of pipe, the delivery tool, was threaded through the insertion tool, and it was used to dislodge the flange from the insertion tool and into the abomasum.
\end{abstract}

Key words: abomasal infusion, rumen bypass

To perform abomasal infusions in dairy cows, a common technique is to insert an infusion line through the rumen cannula, through the sulcus omasi, and into the abomasum (Spires et al., 1975). When using this technique, a flexible plastic flange is typically used to anchor the infusion line in the abomasum (Romo et al., 1996; Knowlton et al., 1998; Benson et al., 2001). As described by Oldick et al. (1997), this flange is folded in the hand and then released after the flange has been passed into the abomasum. A person with an above-average arm length and a strong hand must therefore perform this technique. For large cows, it can be difficult to place a flange by hand, and in those cows it is virtually impossible to ensure that a flange placed by hand is actually in the abomasum. The rumen can be evacuated to facilitate hand placement; however, rumen evacuations are quite time-consuming. To our knowledge, there are no published reports on procedures that can be used to facilitate the placement of abomasal infusion lines. Accurate and secure placement of abomasal infusion lines is essential for the success of research studies using postruminal infusions. A simple, novel technique was developed that can considerably reduce labor requirements and improve precision in abomasal infusion studies.

Received January 3, 2006.

Accepted May 17, 2006.

${ }^{1}$ Corresponding author: learment@wisc.edu
An infusion line was first made using $1.8 \mathrm{~m}$ of flexible polyvinyl chloride (PVC) tubing $(6.4 \mathrm{~mm}$ i.d., $1.6 \mathrm{~mm}$ wall thickness; Fisher Scientific, Pittsburgh, PA). One end of the tubing was passed through a hole in the rumen cannula plug (10 cm center diameter cannula; Bar Diamond, Parma, ID), and the other end was passed through a hole in a Plastisol flange (P-6003; QCM Company, Kent, WA; $12 \mathrm{~cm}$ in diameter, $9 \mathrm{~mm}$ in height). Five holes that were approximately $1.5 \mathrm{~cm}$ in diameter were drilled into each flange to aid in passage of digesta. Additional pieces of clear PVC tubing $(9.6 \mathrm{~mm}$ i.d., 3.2 $\mathrm{mm}$ wall thickness, $13 \mathrm{~mm}$ long) were affixed to the infusion line with cyclohexanone to act as washers to hold the rumen cannula plug and flange in place. This infusion line was found to break occasionally under pressure of the ruminal contractions. Consequently, the flexible PVC tubing was replaced with thicker and more rigid PVC tubing (Nalgene 980 braided clear PVC tubing; $6.4 \mathrm{~mm}$ i.d., $2.3 \mathrm{~mm}$ wall; Fisher Scientific). A completed infusion line is pictured in Figure 1.

The tool developed consisted of 2 pieces, a delivery device and an insertion device. The delivery device (Figure 2A) was a $23-\mathrm{cm}$-long section of $2.5-\mathrm{cm}$ i.d. PVC pipe (Home Depot, Madison, WI). The insertion device (Figure 2B) was made from a 23-cm-long section of 3.8cm i.d. PVC pipe (Home Depot). An approximately $45^{\circ}$ angle was cut into one end of the insertion pipe, and the resulting pipe was $23 \mathrm{~cm}$ at the longest part and 19 $\mathrm{cm}$ at the shortest part. A $10-\mathrm{cm}$-long and $2.5-\mathrm{cm}$-wide groove (wide groove) was then cut lengthwise into the shortest part of the angled end of the pipe. A groove $10 \mathrm{~cm}$ long and $1.6 \mathrm{~cm}$ wide (narrow groove) was cut lengthwise into the longest part of the slanted end of the pipe. Holes were drilled approximately $1 \mathrm{~cm}$ from the blunt end of each tool. A 1-m-long section of nylon cord was tied to each tool through the hole, and the other end was tied to a specimen cup that acted as an anchor to prevent accidental loss inside the animal. The cord on the insertion device additionally provided leverage during placement of abomasal infusion lines as described below. All tool edges were smoothed using a bench grinder and then fine sandpaper prior to use.

The insertion device was used to place the infusion line into the abomasum. The inner wall of the insertion 


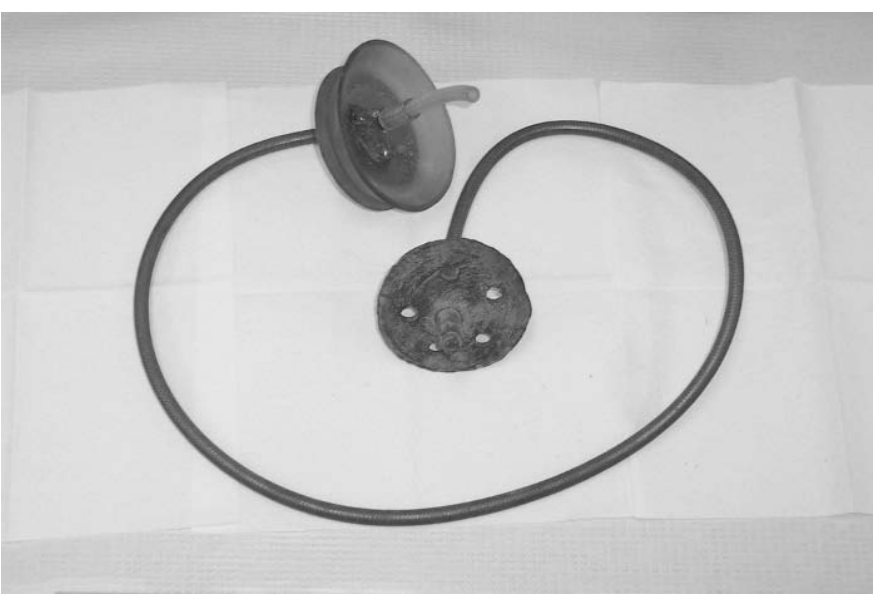

Figure 1. The abomasal infusion line.

device was coated with Safe-Lube breeding lubricant (Nasco, Fort Atkinson, WI) and the flange from the infusion line was folded and placed inside the wide groove of the slanted end of the insertion device. The flange was oriented such that the exit end of the infusion line was inside the folded flange, and the remaining line attached to the rumen cannula plug was threaded through the narrow groove of the insertion tool (Figure $3)$. The right arm was used to place the insertion device inside the rumen cannula. The angled end of the insertion device containing the folded flange was then passed through the sulcus omasi. Once inside the sulcus omasi, the insertion tool was placed inside the abomasal orifice using gentle force applied in a caudal and slightly ventral direction. Often the abomasal orifice was not immediately located, as indicated by resistance to the gentle force applied. The insertion tool was retracted slightly, but not removed from the sulcus omasi, and the direction of the applied force was then adjusted slightly. This procedure was repeated until the abomasal orifice was

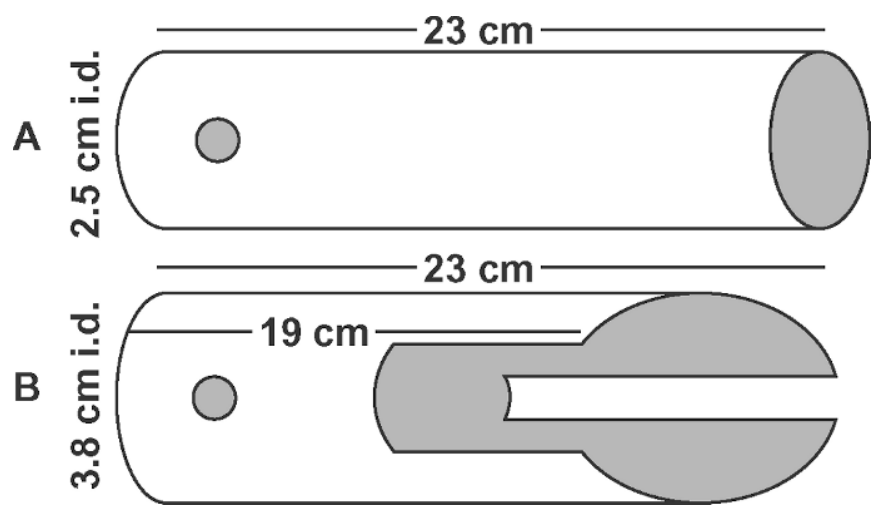

Figure 2. The delivery device (A) and the insertion device (B).

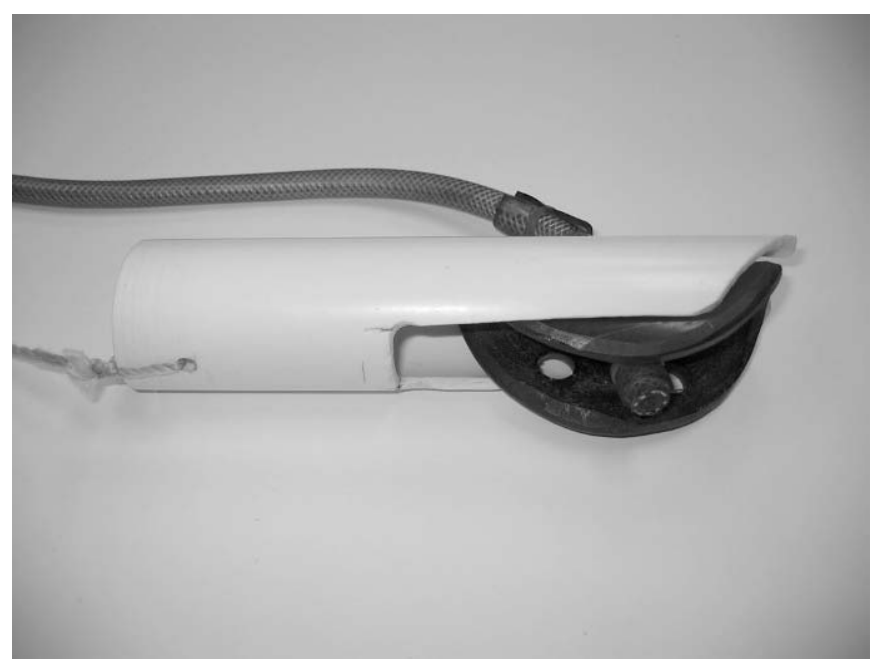

Figure 3. Folded disk from the abomasal infusion line in the insertion device.

located. Passage of the tool through the abomasal orifice was often detected by emission of gas bubbles from the abomasum to the omasum and rumen. Additionally, digesta contents that passed from the abomasum to the rumen through the tool often felt thin and slippery compared with omasal or ruminal digesta. To avoid injury to the animal, excessive force was never applied. Once inside the abomasal orifice, gentle force was applied until only approximately 1 to $2 \mathrm{~cm}$ of the insertion tool remained outside of the sulcus omasi. The right arm was then removed from the rumen to obtain the delivery device, and the right arm containing the delivery device was reinserted in the rumen. Fingers were used to remove any feed particles that had collected in the insertion device, and the free end of the delivery device distal to the nylon cord was placed into the insertion device and against the flange. The nylon cord attached to the insertion device was wrapped around the palm of the right hand to hold the insertion device in place. The base of the right thumb was then used to apply pressure to the protruding portion of the delivery device until the flange was released into the abomasum. Both the delivery and insertion tools were then removed from the abomasal orifice, the omasum, and the rumen. Placement of the flange was then checked by hand. If the flange was found in the omasum, it was removed and the insertion procedure was repeated. However, the flange was usually in the abomasum.

Between 2001 and 2006, 8 people have used these devices and this technique to place abomasal infusion lines in approximately 55 Holstein cows at the University of Wisconsin. Neither partial nor complete rumen evacuation was ever required prior to line placement. The 3 most recent experiments used a total of 29 cows 
with braided PVC infusion lines. Placement of the infusion lines was monitored daily, and the line was found to have been dislodged in 2 instances, both times in the same cow. We therefore believe that this technique was highly successful. Aside from breakage of the clear PVC infusion line, there have been no incidences of failure of these techniques or of injury to the animals as a result of these techniques. Procedures were approved by the Animal Care and Use Committee at the University of Wisconsin.

\section{ACKNOWLEDGMENTS}

The authors would like to thank Ted Gournelos for producing Figure 2. Financial support was provided by US EPA Science to Achieve Results Program Grant \#915435 and from USDA formula funding as part of Regional Project NC-1009.

\section{REFERENCES}

Benson, J. A., C. K. Reynolds, D. J. Humphries, S. M. Rutter, and D. E. Beever. 2001. Effects of abomasal infusion of long-chain fatty acids on intake, feeding behavior, and milk production in dairy cows. J. Dairy Sci. 84:1182-1191.

Knowlton, K. F., T. E. Dawson, B. P. Glenn, G. B. Huntington, and R. A. Erdman. 1998. Glucose metabolism and milk yield of cows infused abomasally or ruminally with starch. J. Dairy Sci. 81:3248-3258.

Oldick, B. S., C. R. Staples, W. W. Thatcher, and P. Gyawu. 1997. Abomasal infusion of glucose and fat-Effect on digestion, production, and ovarian and uterine functions of cows. J. Dairy Sci. 80:1315-1328.

Romo, G. A., D. P. Casper, R. A. Erdman, and B. B. Teter. 1996. Abomasal infusion of cis or trans fatty acid isomers and energy metabolism of lactating dairy cows. J. Dairy Sci. 79:2005-2015.

Spires, H. R., J. H. Clark, R. G. Derrig, and C. L. Davis. 1975. Milk production and nitrogen utilization in response to postruminal infusion of sodium caseinate in lactating cows. J. Nutr. 105:1111-1121. 